\title{
CONCEPÇÕES DE PROFESSORAS DE CIÊNCIAS SOBRE O ENSINO DE CIÊNCIAS
}

\author{
Eliziane da Silva Dávila50 \\ Vanderlei Folmer ${ }^{51}$ \\ Robson Luiz Punte/52
}

\section{RESUMO}

O trabalho docente está atrelado a vários fatores, entre eles, às concepções que os professores possuem e que acabam por refletir na sala de aula. Em função disso, se torna relevante investigar este conhecimento para entender e guiar as práticas pedagógicas. Neste sentido, este trabalho teve como finalidade analisar as concepções de professores de Ciências da rede municipal de educação da cidade de Uruguaiana - RS sobre os objetivos do ensino de ciências e como deve ser sua abordagem em sala de aula. Para este estudo foi aplicado um questionário para as professoras de Ciências desta rede de ensino. Os dados foram analisados a partir da Análise Textual Discursiva (ATD), onde verificamos que os relatos das professoras estavam em consonância com os documentos oficiais de educação do Brasil e com a compreensão de ensino de ciências da contemporaneidade abordado nas pesquisas da área de Educação em Ciências. A partir dos resultados deste estudo podemos refletir em que direção seguir para auxiliar na melhoria dos processos educacionais dentro do ensino de ciências.

Palavras-chave: Ensino de Ciências. Concepções. Ensino Fundamental.

\section{CONCEPTIONS OF SCIENCE TEACHERS ON THE TEACHING OF SCIENCES}

\begin{abstract}
The teaching work is linked to many factors, between them, the conceptions that the teachers have and end up reflecting in class. Based on this, it
\end{abstract}

\footnotetext{
50 Doutoranda no PPG Educação em Ciências: Química da Vida e Saúde da Universidade Federal de Santa Maria (UFSM) - RS. Docente do Instituto Federal Farroupilha (IFFar). E-mail: eliziane.davila@iffarroupilha.edu.br.

51 Doutor em Bioquímica Toxicológica pela Universidade Federal de Santa Maria (UFSM) - RS. Docente na Universidade Federal do Pampa (Unipampa) - Campus Uruguaiana. E-mail: vanderleifolmer@unipampa.edu.br.

52 Doutor em Bioquímica Toxicológica pela Universidade Federal de Santa Maria (UFSM) - RS. Docente na Universidade Federal do Pampa (Unipampa) - Campus Uruguaiana. E-mail: robsonunipampa@gmail.com.
} 
becomes relevant to investigate this knowledge to understand and guide pedagogical practices. In this respect, this work had as a purpose to analyze the conceptions of Science teachers from the municipal network of education from the city of Uruguaiana - RS about the objectives of the Science teaching and how its approach in the classroom should be. For this study a questionnaire was applied for the Science teachers of this teaching network. The data were analyzed from the Discursive Textual Analysis (DTA), where we verify that the reports of the teachers were in accord with the Brazilian official education documents and with the comprehension of the contemporaneity Science teaching approached on researches in the field of Science Teaching. From the results of this study we can reflect about which direction to follow to assist the improvement of the educational processes in the science teaching.

Keywords: Science Teaching. Conceptions. Elementary School.

\section{CONCEPCIONES DE PROFESORAS DE CIENCIAS SOBRE EN LA ENSEÑANZA DE LAS CIENCIAS}

\section{RESUMEN}

El trabajo docente está relacionado a varios factores, entre ellos, a las concepciones que los profesores poseen y que acaban por reflejar en el salón de clase. En función de eso, se torna relevante investigar este conocimiento para entender y guiar las prácticas pedagógicas. En este sentido, el trabajo tiena como finalidad analizar las concepciones de las profesoras de Ciencias de la red municipal de educación de la ciudad de Uruguayana - RS sobre los objetivos de la enseñanza de ciencias y como debe ser su abordaje en el salón de clase. Para este estudio fue aplicado un cuestionario para las profesoras de Ciencias de esta red de enseñanza. Los datos fueron analizados a partir del Análisis Textual Discursivo (ATD), donde verificamos que los relatos de las profesoras estaban en consonancia con los documentos oficiales de educación de Brasil y con la comprensión de enseñanza de ciencias de la contemporaneidad abordada en las investigaciones del área de Educación en Ciencias. A partir de los resultados de este estudio podemos reflexionar en cual dirección seguir para auxiliar en la mejoría de los procesos educacionales dentro de la enseñanza de ciencias.

Palabras clave: Enseñanza de Ciencias. Concepciones. Enseñanza Fundamental.

\section{INTRODUÇÃO}

Vivemos uma época de rápidas mudanças e variados conflitos de ideias, culturas e conhecimentos que atingem a nossa sociedade e proporcionam a alteração de vários paradigmas. Estes fenômenos já são descritos na literatura, onde segundo Krasilchik (2000), os diversos aspectos 
que acarretam em mudanças da sociedade, como política, economia, ciência ou cultura, acabam por refletir na realidade da escola.

Neste cenário, a escola busca se encontrar e atender as demandas de cada época na tentativa de auxiliar na formação do cidadão baseado nas exigências profissionais, sociais e pessoais de cada momento (SOUSA e SÁ CARNEIRO, 2013). O autor John Dewey (1959) destaca ainda, que se o aluno for capaz de atuar de forma cidadã em um espaço reduzido como a própria escola, teremos a garantia de que a sociedade como um todo será digna, admirável e harmoniosa.

Para que a cidadania seja efetivada, é necessário que o estudante disponha de informações que estejam vinculadas com a sociedade para poder compreendê-la e posicionar-se a respeito, tomando decisões adequadas (SANTOS e SCHNETZLER, 2014). Neste sentido, o ensino de ciências pode contribuir por meio de conhecimentos científicos, habilidades, competências e atitudes envolvidas, proporcionando uma alfabetização científica necessária para atuar como cidadão.

O ensino de ciências no Brasil ganhou espaço e importância na educação a partir da segunda metade do século XX, à medida que foi sendo reconhecido o valor da ciência e tecnologia para o desenvolvimento econômico, cultural e social de um país (KRASILCHIK, 2000; SOUSA e SÁ CARNEIRO, 2013). Em virtude disso, este ensino sofreu várias mudanças em seu currículo e objetivos ao longo das décadas, sendo delineado por tendências desencadeadas pelo contexto histórico de cada época principalmente vinculado ao veloz e constante desenvolvimento científico e tecnológico tanto nacional como internacional (DELIZOICOV e ANGOTTI, 1994; SANTOS, BISPO e OMENA, 2005).

Mais do que nunca a Ciência e Tecnologia (C\&T) fazem parte das nossas vidas, se tornando fundamental que ocorra a educação científica para toda a população, em vistas da compreensão da natureza da ciência, seus processos, os principais avanços, benefícios, consequências e limitações. A partir deste entendimento o cidadão estará mais apto a tomar 
decisões numa sociedade tecnológica e poderá se posicionar em relação aos recursos públicos que a nação deve destinar a produção do conhecimento científico e tecnológico (AMABIS, 2005).

Esta tendência reflete também na legislação que orienta o ensino. Até meados da década de 90 a lei 5.692/71 ainda norteava a educação brasileira, com algumas alterações no seu texto nos anos 80. A partir de 1996 entra em vigor uma nova Lei de Diretrizes e Bases da Educação Nacional, a LDB 9.394/96, propondo ao país, uma educação a partir de novas perspectivas políticas e históricas (SOUSA e SÁ CARNEIRO, 2013). O artigo 22 desta lei afirma que a "educação básica tem por finalidade desenvolver o educando, assegurar-Ihe a formação comum indispensável para o exercício da cidadania e fornecer-lhe meios para progredir no trabalho e em estudos anteriores" (BRASIL, 1996, P.8).

Os objetivos da educação no país são revistos, reconhecendo a educação como um instrumento social capaz de possibilitar ao estudante o entendimento das transformações que ocorrem na sociedade e de perceber-se integrante do meio (SOUSA e SÁ CARNEIRO, 2013; SANTOS, BISPO e OMENA, 2005). Vilanova e Martins (2008) destacam que a escola passa a ter responsabilidade de formar o cidadão-trabalhador (VILANOVA e MARTINS, 2008). Estes mesmos autores explicam que para atender a estas prescrições legais e assegurar que ocorram mudanças nas práticas educacionais, o Ministério da Educação (MEC) propôs documentos oficiais de abrangência nacional contendo recomendações para a construção de currículos e orientações para o trabalho do professor. Em relação ao ensino fundamental, foram criados os Parâmetros Curriculares Nacionais (PCNs) com o intuito de servirem como subsídio teórico-metodológico para a implementação de propostas na sala de aula e as Diretrizes Curriculares Nacionais (DCN) de caráter obrigatório, expressando os pressupostos da LDB/96 (RICARDO e ZYLBERSZTAJN, 2008).

Estes documentos trouxeram como finalidade a contextualização e a articulação de saberes, considerando os conhecimentos prévios e 
experiências dos estudantes assim como a abordagem de temas de relevância da realidade. Desta forma, atualmente é imperativo ofertar uma ciência para todos, onde o conhecimento científico e tecnológico esteja acessível à população. Deve-se oportunizar a apropriação crítica destes saberes pelos estudantes, compreender a ciência e tecnologia como uma atividade humana, social e historicamente determinada, percebendo estas como manifestações e produções culturais (DELIZOICOV, ANGOTTI e PERNANBUCO, 2007).

Não se pode, nesse contexto, encarar o ensino de ciências como propedêutico, voltada para uma aprendizagem efetiva num momento futuro. A criança não é cidadã do futuro, mas já é cidadã hoje. Neste sentido, conhecer a ciência é ampliar a sua possibilidade presente de participação social e viabilizar sua capacidade plena de participação social no futuro (PIASSI, 2011). Tal preocupação com um ensino de ciências, que possibilite $\mathrm{o}$ entendimento das questões epistemológicas, históricas e filosóficas que envolvem a ciência e também contribua para o exercício da cidadania, vem sendo sugerida insistentemente nas últimas décadas nos documentos para a "educação científica". Esta expressão é empregada por estudiosos e na legislação do ensino de ciências para designar o "conhecimento necessário para entender os debates públicos sobre as questões de ciência e tecnologia" (HAZEN e TREFIL, 1995).

Um questionamento que parece natural a partir das proposições expostas anteriormente é se o professor de ciências, atribulado por excessivas funções já desempenhadas, objetiva e exerce o ensino de ciências em coerência com os aspectos supracitados. Com base nesse questionamento, o presente trabalho visa investigar a concepção dos professores de Ciências da rede municipal de educação da cidade de Uruguaiana - RS sobre os objetivos do ensino de Ciências e como buscam abordá-lo, pois acreditamos que conhecer as concepções dos professores permite "entender de que maneira estas têm interferido no ensino e 
aprendizagem dos alunos. Além disso, possibilita trabalhar com o professor um repensar sobre sua prática de ensino" (MESQUISTA et al, 2010, p.10).

\section{METODOLOGIA}

O presente trabalho caracteriza-se como uma pesquisa de cunho qualitativa, pois tem como pretensão aprofundar a compreensão dos fenômenos investigados e não testar hipóteses para comprová-las e refutálas no término do estudo (MORAES \& GALIASSI, 2013).

O público-alvo desta pesquisa foram os professores da disciplina de Ciências dos anos finais do ensino fundamental das escolas municipais da cidade de Uruguaiana - RS. A escolha deste público foi intencional, em função da primeira autora deste estudo ter pertencido à rede municipal como docente e suas colegas sugeriam que desenvolvesse alguma formação com elas com o intuito de auxiliá-las a melhorar e refletir suas práticas pedagógicas. A partir desta demanda, foi procurada a Secretaria Municipal de Educação (SEMED) de Uruguaiana para realizar uma formação continuada na área de Ciências, dentro dos encontros mensais de formação pedagógica ofertada por este Órgão. Para iniciar as atividades com este grupo, partimos do pressuposto de que necessitávamos conhecer as concepções deste grupo para então podermos planejar um trabalho adequado. Neste artigo, enfocamos as concepções dos sujeitos envolvidos.

A coleta de dados ocorreu num encontro mensal das docentes de Ciências, cedido pela SEMED, onde aplicamos um questionário contendo as seguintes questões abertas: "Iniciais do nome"; "Idade"; "Sexo"; "Formação Inicial"; "Escolaridade"; "Tempo de serviço no magistério"; ‘Para você, qual o objetivo principal do ensino de ciências?"; "O que o professor de ciências deve buscar trabalhar nas suas aulas?".

Os resultados foram analisados por meio da Análise Textual Discursiva (ATD) (MORAES \& GALIASSI, 2013). Conforme os autores a ATD é vista como um processo auto-organizado que requer um envolvimento intenso com o 
"corpus", para gerar a compreensão de novos entendimentos das informações obtidas na pesquisa, emergindo a partir de uma sequência de três etapas.

Inicialmente ocorre a desmontagem dos textos do "corpus", também denominada de unitarização, que no caso deste estudo, corresponde à análise das informações coletadas através do questionário. Os textos são fragmentados com a finalidade de perceber os sentidos e elementos constituintes, originando as unidades de análise, também denominadas de unidades de significado ou de sentido. Deve ser atribuído um título para estas unidades, que apresente a ideia central de cada unidade para facilitar o estabelecimento de relações e agrupamentos entre elas, etapa da metodologia conhecida como categorização (MORAES \& GALIASSI, 2013).

As categorias da ATD podem ser produzidas através do método dedutivo, indutivo e intuitivo. Neste estudo, utilizamos o método indutivo, que implica produzir as categorias a partir das unidades de análise construídas a partir do "corpus". Consiste no trabalho constante de estabelecer relações entre as unidades de análise, aonde o pesquisador vai organizando grupos de elementos semelhantes, partindo do particular para o geral, originando as categorias emergentes (MORAES \& GALIASSI, 2013).

Neste estudo obtemos as seguintes categorias iniciais:

- Compreender o meio que o cerca e consciência de interação com a natureza.

- Despertar o interesse e curiosidade dos estudantes.

- Temas, assuntos, questões que estejam de acordo com o cotidiano e realidade dos estudantes.

- Estratégias e cotidiano dos estudantes.

Após reflexão sobre a possibilidade de relação entre as categorias acima, chegamos à categoria final:

- O ensino de ciências deve promover o conhecimento científico por meio de estratégias que envolvam o cotidiano do aluno e/ou a realidade 
para compreensão do seu entorno, motivar o estudo e formá-lo um cidadão.

Ao finalizar o processo de categorização, inicia-se a última etapa da ATD que consiste na construção de metatextos através da transformação das categorias em textos, momento no qual o pesquisador exprime suas construções e interpretações pessoais, porém sempre tendo como referência às informações obtidas com os sujeitos da pesquisa, mantendo fidelidade e respeito às mesmas (MORAES \& GALIASSI, 2013). O metatexto deste estudo é que compõe os resultados e discussão do próximo tópico deste material.

\section{RESULTADOS E DISCUSSÃO}

Os docentes participantes da produção dos dados exerciam magistério na rede municipal de Uruguaiana. Contamos nesta oportunidade com 25 professores de Ciências que foram convidados a responder o questionário. Aceitaram participar desta pesquisa apenas professoras com idades entre 26 e 55 anos, totalizando 14 questionários respondidos.

\section{As concepções sobre Ensino de Ciências dos Professores}

A categoria final "O ensino de ciências deve promover 0 conhecimento científico por meio de estratégias que envolvam o cotidiano do aluno e/ou a realidade para compreensão do seu entorno, motivar o estudo e formá-lo um cidadão", carrega consigo várias percepções e características das respostas das professoras.

Notamos que as docentes não concebem o ensino de ciências como sendo uma tarefa de transmissão de conhecimentos embasada na memorização do conteúdo, mas sim, fomentam a construção do conhecimento enfatizando a formação cidadã dos educandos. Este é um aspecto importante, pois atende à finalidade preconizada na LDB (1996) e 
os objetivos dos PCNs (1998) e das DCNs (2013), que quando tratam do ensino de ciências, primam pelo preparo para o exercício da cidadania.

Pesquisadores da área de Educação em Ciências também enfatizam a importância da formação cidadã. Delizoicov, Angotti e Pernambuco (2002) mencionam que os professores ao se preocuparem em formar um cidadão, estão promovendo uma ciência para todos, democratizando o ensino de ciências. Chassot (2011) e Santos \& Schnetzler (2014) explicam que a cidadania requer que o indivíduo atue na sociedade e para tal é necessário que ele disponha de informações, isto inclui o conhecimento científico, para posicionar-se e propor soluções adequadamente. Faz-se importante que o professor auxilie o estudante a se apropriar deste conhecimento para que possa tanto compreender esses progressos científicos e tecnológicos quanto verificar a relação deste saber com o seu cotidiano e participar ativamente na sociedade, zelando pelo bem individual, coletivo e do meio ambiente (SANTOS e SCHNETZLER, 2014).

As professoras deste estudo demonstraram ter esse entendimento, pois consideram que o ensino de ciências deve oportunizar aos estudantes a compreensão do mundo que o cerca, da sua realidade, o respeito pelo outro e pelo meio ambiente e que este conhecimento científico possa contribuir na melhoria da qualidade de vida e na formação cidadã, como podemos visualizar nos relatos a seguir.

Professora 8 - "O objetivo principal do ensino de ciências é buscar o conhecimento acerca do meio onde estamos inseridos, visando o respeito para com outro e com o meio ambiente." Professora 12 - "Preparar o aluno para a vida no seu dia-dia (ter qualidade de vida)."

Concepção semelhante ao desta pesquisa verificou-se nos estudos de Cunha e Campos (2010) com professores de Ciências e Biologia de um município da Grande São Paulo. Ademais, esta concepção de ensino de ciências é condizente com os atuais objetivos do ensino de ciências 
presentes nos documentos oficiais (PCNs (1998); DCN (2013)) onde prezam que os estudantes devem ter a compreensão do mundo natural e suas transformações, situando o ser humano como indivíduo participativo e integrante do universo.

Segundo Chassot (2011) a responsabilidade dos professores de ciências é procurar que os alunos e alunas se transformem em homens e mulheres críticos, transformadores do mundo em que vivemos. Assim os estudantes devem perceber que a ciência é uma linguagem para facilitar a leitura do mundo, uma construção humana, logo mutável e falível. Entender a ciência é uma forma de compreender o mundo que os cerca, por isso devemos promover a alfabetização científica dos estudantes.

De acordo com Sasseron e Carvalho (2011) proporcionar a alfabetização científica mencionada anteriormente vem sendo concebida ao longo dos anos como uma das finalidades mais importantes do ensino de ciências para toda a formação básica do sujeito. Ela é conhecida sob o lema "Ciência para todos", pois se defende que o conhecimento científico e tecnológico deve ser proporcionado a todas as pessoas para compreenderem a realidade em que estão inseridos e poderem participar critica e ativamente na sociedade (DELIZOICOV, ANGOTTI e PERNAMBUCO, 2002). A alfabetização científica deve ser difundida em todas as culturas e setores da sociedade para melhorar o engajamento dos cidadãos nas tomadas de decisões em relação à aplicação dos novos conhecimentos advindos da C\&T (BUDAPESTE e SANTO DOMINGO, 2003).

Uma das maneiras de contribuir com a efetivação da alfabetização científica no âmbito escolar é através da contextualização dos saberes disciplinares. As DCN (2013) trazem como necessário a contextualização dos conteúdos escolares através da valorização das experiências dos alunos, "articulando vivências e saberes dos estudantes com os conhecimentos historicamente acumulados e contribuindo para construir as identidades dos estudantes". Os PCNs (1998) não abordam de forma direta o termo contextualização, porém existem vários elementos que remetem a 
um ensino contextualizado, como por exemplo, a organização do currículo por eixos temáticos que proporciona a abordagem do conteúdo escolar de maneira integrada, assim como a proposta dos temas transversais trazendo a realidade sociocultural do aluno para o ambiente escolar (KATO e KAWASAKI, 2011).

Neste estudo verificamos que as professoras concebem que o ensino de ciências deve ser promovido de maneira contextualizada, partindo do cotidiano, da realidade dos estudantes e do interesse dos mesmos. Concepção semelhante foi verificada nos estudos de Assis e Borges (2001) com professores da educação básica de Belo Horizonte e nas investigações de Kato e Kawasaki (2011) com professores de Ciências e de Biologia do Estado de São Paulo em um curso de formação continuada, porém, além deste entendimento, outras concepções foram identificadas por estes autores, mas que no presente estudo não foram encontradas.

Giassi (2009) obteve dados distintos ao desta pesquisa ao trabalhar com professores de Biologia da Rede Estadual de Ensino de Criciúma - SC. Em suas investigações percebeu que os docentes procuravam trabalhar de maneira contextualizada, contudo verificou-se uma preocupação maior com o aprendizado dos conteúdos escolares em detrimento da realidade de seu contexto de vida. Giassi e Moraes (2010) mencionam que os professores podem ter várias interpretações sobre contextualização a partir dos documentos oficiais educacionais, podendo ter como consequência o entendimento da contextualização como uma ferramenta para abordar os conteúdos escolares e não com a finalidade de compreender 0 conhecimento "a partir de sua complexidade e seus entrelaçamentos políticos, sociais, históricos, econômicos, culturais, entre outros". Também devemos cuidar para não interpretar e tratar a contextualização como uma mera exemplificação do cotidiano, servindo apenas como um "pano de fundo" para desenvolver os conteúdos escolares, senão, como manifestado por Ruppenthal (2013), desta maneira não será proporcionado ao estudante 
um momento para pensar e refletir, agindo passivamente, onde "ouve e aceita, mas não tem voz".

Conforme apontado nas DCNs (2013) é responsabilidade dos profissionais da educação, entre eles o professor, de despertar nos estudantes o interesse por experimentar situações de aprendizagem como conquista individual e coletiva, embasadas no contexto particular e local. Chassot (2011) coloca que a cidadania só poderá ser exercida se o estudante tiver acesso ao conhecimento, cabendo aos educadores promover a educação científica e mostrar os conhecimentos da área, os quais devem ser e estar encharcados na realidade.

Outro aspecto relacionado aos conhecimentos científicos se refere aos saberes específicos, destacados por algumas professoras dentro de suas percepções sobre 0 ensino de ciências considerado por elas importantes para serem desenvolvidos durante a prática de ensino. Essa concepção demonstra estarem de acordo com o cotidiano e realidade dos estudantes, como por exemplo, assuntos relacionados à educação em saúde, que podem ser visualizados nos relatos abaixo:

Professora 10 - "objetivo principal é ensinar o que é significativo para a vida dos alunos, seu dia-a-dia, o que tem importância realmente. Ex: doenças, prevenção, DSTs, autoconhecimento, sexualidade, saúde, ..."

Professora 14 - "Promover a saúde e o bem-estar, interagir com o ambiente de forma positiva e participativa".

Nos relatos é possível observar que as professoras estão focando na promoção da saúde, pois não mencionam somente assuntos relacionados à doença, mas para a compreensão e cuidado de seu corpo, para terem hábitos saudáveis e uma melhor qualidade de vida e em relação à questão sexual. Observa-se que estas concepções estão em consonância com os objetivos do eixo temático "Ser Humano e Saúde" dos Parâmetros Curriculares Nacionais (PCNs) sendo observado no texto recortado abaixo. 
Promover a conscientização dos alunos para o direito à saúde, sensibilizá-los para a busca permanente da compreensão de seus condicionantes e capacitá-los para a utilização de medidas práticas de promoção, proteção e recuperação da saúde ao seu alcance (BRASIL, 1998, p. 269).

O relato da professora 10, também é condizente com outro eixo temático dos PCNs, a "Orientação sexual" ao mencionar as DSTs e sexualidade. Segundo este documento, ao se considerar estes assuntos como importantes para serem trabalhados em sala de aula, se estará auxiliando na promoção da saúde dos estudantes, pois ao ter conhecimento da sua sexualidade amplia-se a consciência sobre os cuidados necessários para a prevenção de diversas situações, como gravidez na adolescência, abuso sexual, DSTs, entre outros.

O relato da professora 14 apresenta outra característica que pode ser observada em relação ao meio ambiente, que também foi visualizada em outros relatos, conforme seguem abaixo:

Professora 5 - "Levar o aluno entender a vida no planeta e reconhecer que é preciso colaborar para a preservação deste planeta."

Professora 9 - "Fazer com que o aluno compreenda um pouco mais o mundo em que ele vive, que desperte nele a consciência de preservação e de seu ambiente, que ele conhecendo, adquira respeito pelo outro e pela natureza, que ele queira aprofundar-se nas diferentes áreas da Ciência."

Observamos que para estas professoras, um dos objetivos centrais do ensino de ciências é levar o estudante a compreender o meio ambiente, tanto o que está inserido quanto os globais, para poder adquirir uma consciência ambiental e desta forma passar a respeitar e auxiliar na preservação do meio. Novamente as respostas das professoras vão ao encontro dos PCNs, só que neste caso para o eixo temático "Vida e Ambiente" que apresenta como finalidade ao estudante: "perceber-se 
integrante, dependente e agente transformador do ambiente, identificando seus elementos e as interações entre eles, contribuindo ativamente para a melhoria do meio ambiente (BRASIL, 1998, p. 7)."

Esses relatos sugerem a abordagem da educação ambiental nas escolas, pois se observa a intenção de promover a conscientização da relação homem/natureza, a formação de valores e atitudes adequadas com o meio ambiente como preconizado na LDB (1996), PCNs (1998) e DCNs (2013).

Outro conhecimento científico específico observado nas falas das professoras, diz respeito aos fenômenos naturais, como expresso abaixo:

Professora 11 - "Saber observar os fenômenos da natureza e relacioná-los com a ciência, para entender seus processos de transformação".

Para esta professora o ensino de ciências deve auxiliar os estudantes a compreenderem melhor a natureza e as leis naturais que a regem através dos conhecimentos científicos da disciplina. Os estudantes precisam ter noção que os fenômenos naturais são aqueles em que não ocorre interferência do ser humano e que estamos sujeitos a eles. O professor de ciências deve estar atento que no senso comum, um fenômeno natural pode ser sinônimo de desastre natural e que deve auxiliar na reconstrução destes conceitos. O estudante precisa relacionar os conhecimentos científicos, compreender como são os processos da natureza, as influências que exercem sobre os seres vivos, nas sociedades e na qualidade de vida dos seres humanos, além das consequências da intervenção humana nos fenômenos naturais.

De acordo com os PCN's (1997) o aluno deve perceber que os conhecimentos produzidos pela ciência contribuem para a compreensão do planeta e de suas transformações, além de mostrar que o homem é um integrante do meio ambiente e da sociedade em que está inserido. Pode passar a valorizar e ter atitudes de respeito e cuidado com o mesmo, 
auxiliando desta forma com a conservação da natureza e com tomada de decisões mais responsáveis.

Dentro desta perspectiva de compreensão da natureza verificamos outro relato como segue abaixo:

Professora 7 - "É ensinar sobre o ser humano e os seres vivos e tudo que o cerca de maneira que haja reflexão de que são assuntos que se integram."

Percebemos que a professora 7 entende que o ensino de ciências deve proporcionar uma visão integrada de mundo como preconizado nos PCNs, criando condições para o estudante poder estabelecer relações entre os múltiplos saberes. Através de uma abordagem sistêmica, pode-se levar os estudantes a compreender que a vida está condicionada a um equilíbrio dinâmico e que a sua compreensão perpassa todas as áreas do conhecimento. A partir deste trabalho, novamente estará contribuindo para a formação de uma consciência ambiental do estudante assim como a abordagem sobre fenômenos naturais analisados anteriormente.

Assim como os saberes específicos identificados em algumas falas, também foi verificada a importância dada por algumas professoras de considerar as ideias prévias dos estudantes em sala de aula, como ilustrado na fala a seguir:

Professora 4 - "Através do ensino de ciências que o aluno seja capaz de aplicar e aprimorar os conhecimentos-prévios e relacionar com o cotidiano."

Este relato está em consonância com os documentos oficiais educacionais brasileiros. Os PCNs destacam que devem ser consideradas em sala de aula as explicações intuitivas, o senso comum dos alunos por serem conceitos importantes que importam e interferem na alfabetização científica. 
De acordo com Florentino (2004); Teixeira e Sobral (2010) cada estudante carrega consigo conhecimentos prévios e representações que foram construídos na sua vida cotidiana, familiar, cultural como uma maneira de compreender e explicar o mundo, bem como para a necessidade de elucidar problemas da sua realidade. Conforme Driver (1989) e Schnetzler (1992) estas concepções prévias podem ser diferentes das ideias a serem ensinadas interferindo e influenciando na aprendizagem. Também por inúmeras vezes podem apresentar-se resistentes à mudança, visto que para o estudante, suas ideias fazem sentido, tornando-se como Bachelard (2005) e Bastos (2013) mencionam um obstáculo ao processo de aprendizagem (obstáculos epistemológicos). Por isso, é fundamental e imprescindível explicitarmos aos nossos alunos a responsabilidade de que devem assumir pela sua aprendizagem como também os docentes organizarem sua prática pedagógica a partir das concepções já existentes (SCHNETZLER, 1992).

Além de levar em consideração as ideias prévias dos estudantes, também foi mencionado pelas professoras o aprimoramento de habilidades dentro do ensino de ciências. A seguir, trazemos um relato com essa concepção:

Professora 5 - "Desenvolver no aluno as habilidades de investigar, observar, compreender, concluir e aplicar".

Tanto os PCNs (1998) como as DCNs (2013) trazem como orientação para o ensino fundamental 0 desenvolvimento de conhecimentos, habilidades, atitudes e valores para construir no estudante uma visão crítica do mundo e para saber viver em sociedade.

Maia e Justi (2008) mencionam que o desenvolvimento de habilidades é necessário para a compreensão da própria ciência e deve ser trabalhado ao longo dos anos escolares através de atividades que instiguem o aprendizado sobre os processos de investigação em ciências, auxiliando o desenvolvimento do raciocínio do estudante. 
Outra característica verificada na categoria final foi em relação à abordagem dos conhecimentos científicos em sala de aula. As professoras concebem que devem ser desenvolvidos por meio de temáticas:

Professora 4 - "Trabalhar temáticas significativas que possam colaborar com a realidade em que vivemos, esclarecendo de forma objetiva e significativa."

As professoras destacam que as temáticas devem emergir dos alunos e tenham como características: que sejam relevantes, significativas e interessantes para os estudantes; que auxiliem na compreensão tanto da realidade em que o aluno está inserido quanto da sociedade em geral; que despertem a curiosidade para assim proporcionar o diálogo; que auxiliem o estudante a reconhecer 0 mundo pelas lentes da ciência. Trazemos alguns relatos para ilustrar esta concepção:

Professora 6 - "Deve trabalhar temas que provoque a curiosidade dos alunos. Temas que auxiliem o aluno em conhecer o seu meio, seu corpo e as tecnologias que a sociedade produz e produziu (história) para benefício dela."

Professora 10 - "Deve buscar trabalhar assuntos que despertem interesse e curiosidade em seus alunos, assuntos que eles possam sugerir, debater."

A utilização de temáticas em sala de aula é recomendada pela legislação vigente. As DCNs (2013) mencionam que devem ser abordados temas abrangentes e contemporâneos que contemplem tanto situações globais, regionais e locais, quanto individuais, proporcionando aos estudantes maior compreensão e interesse pela realidade em que vivem.

Fagundes (2013) salienta que ao se utilizar temas de interesse dos estudantes, além de estimular a participação e o interesse deles, também possibilita mostrar as situações explicadas através dos saberes científicos, evidenciando a importância desses conhecimentos para o entendimento do 
seu entorno, da sua vida e para a sua atuação na sociedade como cidadão.

Entretanto, um dado que nos chamou a atenção foi que nenhuma das falas analisadas contemplou a abordagem do ensino de ciências na perspectiva interdisciplinar ou da transversalidade como sugerido nos documentos oficiais. Levantamos algumas hipóteses para esta razão. A transversalidade envolve uma prática interdisciplinar e os professores podem sentir dificuldades para trabalhar desta forma em sala de aula, em função do desconhecimento do tema, inexperiência, e/ou pela formação inicial que tiveram. As ideias de transversalidade/interdisciplinaridade dos professores da escola também podem estar interferindo no desenvolvimento deste tipo de atividade. Ocampo, Santos e Folmer (2016) mencionam em sua pesquisa que se os professores tiverem um conceito simplista de interdisciplinaridade, isso pode levar os educadores a terem receio da prática interdisciplinar.

Outra hipótese relacionada à ausência de trabalho integrado entre os docentes das diferentes disciplinas pode estar vinculada às condições de trabalho, como por exemplo, a falta de tempo para ocorrer reuniões, prejudicando o diálogo entre eles; muita carga horária de aula; infraestrutura da instituição e questões salariais. Alguns destes argumentos foram encontrados nos relatos de $88 \%$ dos professores da Fronteira Oeste do Rio Grande do Sul participantes do estudo de Ocampo, Santos e Folmer (2016).

Também acreditamos que a estrutura curricular da escola pode estar influenciando para que não ocorra interdisciplinaridade, tendo um conteúdo programático a ser cumprido no decorrer do ano e o professor não conseguindo desvincular-se do mesmo, seguindo-o de forma rígida e sem interação com outras áreas do conhecimento. Azevedo e Andrade (2007) citam que para ocorrer interdisciplinaridade no ambiente educacional é necessária uma reestruturação curricular para o saber escolar ser produzido de maneira crítica e coletiva. A prática pedagógica 
interdisciplinar necessita envolver atributos de associação, colaboração, cooperação, complementação e integração entre as disciplinas para dar um novo significado à práxis docente (FAZENDA, 1979).

Ao analisarmos todos os dados desta pesquisa, acabamos por refletir sobre os resultados divulgados nas avaliações de larga escala, como o Programme for International Student Assessment (PISA), que teve como enfoque no ano de 2015 a disciplina de Ciências (OECD, 2017). Ao divulgar seus resultados no ano de 2016, mostrou o Brasil ranqueado entre os piores países em desempenho na área.

Imagina-se que a legislação educacional brasileira tem se preocupado na melhora do desempenho dos estudantes, um exemplo disso é a meta 7 do Plano Nacional de Educação (PNE) (2014). Então, se os professores seguissem as premissas da legislação, deveríamos ter uma melhora no desempenho dos estudantes. Entretanto, não é este cenário que estamos presenciando no país. Neste trabalho verificamos que as respostas das docentes estão condizentes com os documentos oficiais em vigor. Porém, como não observamos as aulas destas docentes, não podemos afirmar que as mesmas estão conseguindo desenvolver plenamente suas práticas pedagógicas em consonância com as concepções aqui analisadas. Ressaltamos isso em função do estudo de Pessano et al. (2014) que averiguaram uma diferença entre a concepção de ciência e as estratégias desenvolvidas em sala de aula por professores de uma escola pública do município de Uruguaiana-RS, mesma cidade da presente pesquisa.

Esta situação pode estar vinculada a diversos fatores que possam estar dificultando à práxis pedagógica. Nesse contexto, Coutinho et al. (2012) ao realizar uma investigação sobre a percepção dos docentes de Ciências, Matemática e Educação Física das escolas municipais da mesma cidade do nosso estudo, em relação às suas práticas educacionais, identificaram alguns fatores que dificultam o trabalho destas docentes, entre eles estão os problemas de infraestrutura (41\%) como falta e/ou espaços físicos 
inadequados, falta de material didático e quantidade excessiva de alunos em sala de aula; disciplina dos estudantes (28\%); família (13\%); desvalorização do professor (13\%); deficiência na formação (3\%) e aprendizado (2\%).

Por fim, destacamos que a importância de conhecer as percepções dos atores sociais sobre uma determinada questão é de grande relevância para o entendimento situacional de um determinado fenômeno. Pessano et al. (2014) destaca que:

\begin{abstract}
A investigação das concepções é de fundamental importância, especialmente quando tratamos de profissionais da educação, os quais possuem o papel de contribuir para a formação dos indivíduos, tornando-os cidadãos capazes de mudar a realidade. Acreditamos que, a partir das concepções, possamos criar alternativas que possibilitem a reconstrução do conhecimento, permitindo que novas concepções sejam estabelecidas, visando favorecer os processos educacionais e a alfabetização científica (PESSANO, et al, 2014, p.61).
\end{abstract}

\title{
CONSIDERAÇÕES FINAIS
}

Neste artigo buscamos resgatar as concepções das professoras de Ciências da rede municipal de Uruguaiana - RS sobre o ensino de ciências. Constatamos que as concepções atendem às finalidades e princípios preconizados nos documentos oficiais da educação brasileira, assim como aos objetivos e temáticas sugeridos nos PCNs.

De acordo com as professoras, o ensino de ciências deve considerar o cotidiano, as vivências e saberes dos estudantes dentro da sala de aula para abordar os conhecimentos científicos, mostrando que este saber é importante para o entendimento da sociedade na qual estamos inseridos, dos processos e produtos da ciência e tecnologia que se fazem presente os dias atuais. Um ensino voltado para estes aspectos contribui para a formação da cidadania do estudante, além de torná-lo mais relevante e interessante, propiciando um maior aprendizado. Um ensino que esteja preocupado em formar cidadãos está ajudando a democratizar a educação científica, pois entende que deve ser oferecido o conhecimento 
científico para todas as pessoas. Auxiliar os estudantes a compreender 0 mundo através das lentes da ciência, estará promovendo a alfabetização científica desses sujeitos, estando mais preparado para tomada de decisões de caráter individual, coletivo e/ou em prol do meio ambiente, tendo consciência de suas atitudes perante a natureza.

Além de levarem em consideração a articulação dos conhecimentos científicos com as ideias e o cotidiano dos estudantes, também se constatou nos relatos, a preocupação em abordar estes saberes de forma que despertasse o interesse e curiosidade dos estudantes, envolvendo-os em situações de discussões, debates, onde 0 estudante fosse 0 protagonista de sua aprendizagem. A abordagem dos conhecimentos científicos por meio de temáticas foi a forma mais mencionada entre as professoras deste estudo para promover o ensino de ciências de forma contextualizada, relevante, que levasse os estudantes a discussões de assuntos pertinentes tanto a sua realidade como temas de escala global, regional e/ou local.

A partir dos resultados deste estudo, podemos planejar e desenvolver formações continuadas partindo das concepções destas docentes, onde possamos trabalhar de forma conjunta (pesquisadores e docentes) na construção e reconstrução de conceitos, metodologias e estratégias de ensino com a finalidade de melhorarmos cada vez mais os processos de ensino-aprendizagem, refletindo no desempenho dos estudantes.

Também parece pertinente que um próximo passo seja verificar as correlações entre a percepção e a prática das docentes em relação ao uso de temáticas. A partir disso, poderemos averiguar como realmente estão sendo desenvolvidas e quais os referenciais utilizados para podermos contribuir neste processo, dentro da realidade de cada instituição escolar.

Entretanto, um fator limitante encontrado nesta pesquisa foi quanto a falta de literatura para discutir as falas das docentes no que concerne à concepção de ensino de ciências. Foram achados vários artigos referentes a esta abordagem, mas com docentes de pedagogia que atuam no 
Ensino Fundamental I. Em relação às docentes com formação na área de Ciências, foram encontrados numerosos artigos enfocando as concepções sobre a natureza do conhecimento científico. Ressaltamos que tais trabalhos apontam para a necessidade de serem realizados mais estudos onde se busque melhor compreender a concepção dos professores sobre o Ensino de Ciências, tal como o realizado aqui.

\section{AGRADECIMENTOS}

Às professoras participantes do estudo, a Secretaria Municipal de Educação de Uruguaiana - RS, a Universidade Federal de Santa Maria (UFSM), aos auxílios financeiros recebidos pela CAPES, CNPq, FAPERGS, INCTEN, FINEP e ao Instituto Federal Farroupilha (IFFar) pelo Programa Institucional de Incentivo à Qualificação Profissional dos Servidores do IFFar (PIIQP).

\section{REFERÊNCIAS}

AMABIS, J. M. A premência da educação científica. In: WERTHEIN, J. e CUNHA, C. org. Educação Científica e Desenvolvimento: o que pensam os cientistas. Brasília: UNESCO. Instituto Sangari, p. 235, 2005.

ASSIS, M e BORGES, O. Como os professores concebem o ensino de ciências ideal. In: III Encontro Nacional de Pesquisa em Educação em Ciências, Atibaia - SP, 2001. Disponível em: <http://www.nutes.ufrj.br/abrapec/iiienpec/Atas\%20em\%20html/o37.htm>. Acesso em: 16 de outubro de 2016.

AZEVEDO, M. A. R. e ANDRADE, M. F. R. O conhecimento em sala de aula: a organização do ensino numa perspectiva interdisciplinar. Educar, Curitiba, n. 30, p. 235-250, 2007.

BACHERLARD, G. A formação do espírito científico: contribuição para uma psicanálise do conhecimento. Rio de Janeiro: Contraponto. $5^{a}$ reimpressão. P. 316, 2005.

BASTOS, F. Construtivismo e o ensino de ciências. In: NARDI, R. et al. Questões atuais no ensino de ciências. $2^{a}$ Ed. São Paulo: Escrituras Editora. p. 143, 2013.

BRASIL. Lei $n^{\circ} 9.394$ Diretrizes e Bases da educação nacional: promulgada em 20/12/1996. Brasil. Ed. do Brasil. 1996. 
BRASIL. Secretaria de Educação Fundamental. Parâmetros curriculares nacionais: terceiro e quarto ciclos do ensino fundamental (Tema Transversal Saúde). Secretaria de Educação Fundamental - Brasília: MEC/SEF, 1998.

BRASIL. Secretaria de Educação Fundamental. Parâmetros curriculares nacionais: terceiro e quarto ciclos do ensino fundamental (Tema Transversal Orientação Sexual). Secretaria de Educação Fundamental - Brasília: MEC/SEF, 1998.

BRASIL. Secretaria de Educação Fundamental. Parâmetros curriculares nacionais: terceiro e quarto ciclos do ensino fundamental (Ciências Naturais). Secretaria de Educação Fundamental - Brasília: MEC/SEF, 1998.

BRASIL. Lei n.13.005, de 25 de junho de 2014. Aprova o Plano Nacional de Educação - PNE e dá outras providências. Diário Oficial da União, Brasília, DF., 25 jun 2014.2 Disponível em: http://www.planalto.gov.br/CCIVIL_03/_Ato2011-2014/2014/Lei/L13005.htm. Acesso em 27 de março de 2017.

BRASIL. Ministério da Educação. Secretaria de Educação Básica. Diretrizes Curriculares Nacionais Gerais da Educação Básica. Secretaria de Educação Básica. Brasília: MEC, SEB, DICEI, 2013.

BUDAPESTE e SANTO DOMINGO. A ciência para o século XXI - Uma nova visão e uma base de ação. Brasília: UNESCO. ABIPTI, p. 71. 2003.

CHASSOT, A. Alfabetização científica e cidadania. In: Alfabetização científica: questões e desafios para a educação. $5^{a}$ ed. rev. ljuí: Ed. Unijuí. p. $368,2011$.

COUTINHO, R. X.; SANTOS, W. M.; FOLMER, V.; ROCHA, J. B. T.; PUNTEL, R. L. Percepções de professores de ciências, matemática e educação física sobre suas práticas em escolas públicas. Revista Ciências \& Ideias, V. 4, N. 1 , $1-$ p.18, Jul. 2012.

CUNHA, F. M. e CAMPOS, L. M. L. O discurso e a prática pedagógica de professores de ciências do ensino fundamental. In: PIROLA, N. A. Ensino de Ciências e Matemática, IV: temas de investigação. São Paulo: Ed. UNESP; São Paulo: Cultura Acadêmica, p. 244, 2010.

DELIZOICOV, D. e ANGOTTI, J. A. P. Metodologia do Ensino de Ciências. São Paulo: Cortez, p. 203, 1994.

DELIZOICOV, D.; ANGOTTI, J. A. P. e PERNAMBUCO, M. M. Ensino de Ciências: fundamentos e métodos. São Paulo: Cortez. P. 364, 2002.

DEWEY, J. Democracia e Educação. $3^{a}$ ed. São Paulo: Nacional, 1959.

DRIVER, R. Student's conceptions and learning of Science. International Journal of Science Education. V. 11, n esp, p. 481 - 490. 1989.

FAZENDA, I. Integração e interdisciplinaridade no ensino brasileiro: efetividade ou ideologia? São Paulo: Loyola, 1979. 
FAGUNDES, E. M. O uso de temas cotidianos para o ensino de ciências nos anos iniciais do ensino fundamental. Dissertação (Programa de Pós Graduação em Ensino de Ciência e Tecnologia). Universidade Tecnológica Federal do Paraná. 2013. 122 p.

FLORENTINO, A. Fundamentos da educação 1. v.1, Rio de Janeiro: Fundação Cecierj, 2004. 153p.

GIASSI, M. G. A Contextualização no Ensino de Biologia: um estudo com professores de escolas da rede pública estadual do município de Criciúma SC. Tese de doutorado (Programa de Pós Graduação em Educação Científica e Tecnológica). Universidade Federal de Santa Catarina. 2009. 259 p.

GIASSI, M.G. e MORAES, E. C. Um estudo sobre a contextualização do ensino nos PCNEN e na proposta curricular de Santa Catarina. In: Simpósio Internacional e Fórum Nacional de Educação, 4, 7, 2010, Torres. Anais. Torres, 2010.

HAZEN, R. M. e TREFIL, J. Saber ciência. São Paulo: Cultura, 1995.

KATO, D. S.; KAWASAKI, C. S. As concepções de contextualização do ensino em documentos curriculares oficiais e de professores de ciências. Ciência \& Educação, Bauru, v.17, n.1, p. 35-50, 2011.

KRASILCHIK, M. Reformas e Realidade: o caso do ensino de ciências. São Paulo em Perspectiva. V. 14, n. 1, 85 - 93 p. 2000.

MAIA, P. F. e JUSTI, R. Desenvolvimento de habilidades no ensino de ciências e o processo de avaliação: análise da coerência. Ciência \& Educação. V. 14, n. 3, p. 431-50, 2008.

MESQUITA, M. da G. B. de F.; PAIXÃO, H. S.; GOMES, P. N. N. Crenças e concepções de professores de Matemática interferindo no processo ensinoaprendizagem. X ENEM - ENCONTRO NACIONAL DE EDUCAÇÃO MATEMÁTICA: Educação, Matemática, Cultura e Diversidade. Anais. Comunicação Científica, p.1-11, 2010.

MORAES, R.; GALIAZZI, M. C. Análise Textual Discursiva. ljuí: UNIJUÍ, 2013.

OCAMPO, D. M.; SANTOS, M. E. T. e FOLMER, V. A interdisciplinaridade no ensino é possível? Prós e contras na perspectiva de professores de Matemática. Bolema. V. 30, n56, p. 1014 - 1030. Dez. 2016.

ORGANISATION FOR ECONOMIC CO-OPERATION AND DEVELOPMENT. PISA 2015: Results in focus. Disponivel em: http://www.oecd.org/pisa/pisa-2015results-in-focus.pdf. Acesso em 27 de março de 2017.

PIASSI, L. P. Educação científica no ensino fundamental: os limites dos conceitos de cidadania e inclusão veiculados nos PCN. Ciência \& Educação. V. 17, n. 4, p. 789-805, 2011. 
PESSANO, E. C.; MULLER, I. G.; QUEROL, M. M.; FOLMER, V.; PUNTEL, R. Concepções de Ciência de educadores e estudantes e identificação das estratégias do ensino de Ciências em uma escola localizada no interior da Fundação de Atendimento Socioeducativo em Uruguaiana-RS. Revista Eletrônica de Educação, v. 8, n. 2, p. 58-80. 2014.

RICARDO, E. C. e ZYLBERSZTAJN, A. Os Parâmetros Curriculares Nacionais para as ciências do ensino médio: uma análise a partir da visão de seus elaboradores. Investigações em Ensino de Ciências. V 13, n. 3, p. 257-274. 2008.

RUPPENTHAL, R. O ensino do sistema respiratório através da contextualização e atividades práticas. Programa de Pós Graduação de Educação em Ciências, Química da Vida e Saúde. Dissertação de Mestrado - Universidade Federal de Santa Maria, 2013.

SANTOS, P. O.; BISPO, J. S. e OMENA, M. L. R. A. O ensino de ciências naturais e cidadania sob a ótica de professores inseridos no programa de aceleração de aprendizagem da EJA - Educação de Jovens e Adultos. Ciência \& Educação. V. 11, n. 3. P. 411 - 426. 2005.

SANTOS, W. L. P. e SCHNETZLER, R. P. Educação em Química: Compromisso com a cidadania. $4^{a}$ ed. ljuí: Ed. Unijuí. 2014. 159 p.

SASSERON, L. H. e CARVALHO, A. M. P. Alfabetização científica: uma revisão bibliográfica. Investigações em Ensino de Ciências, v. 16, n. 01, p. 59 - 77 , 2011.

SCHNETZLER, R. P. Construção do conhecimento e ensino de ciências. Em Aberto. Brasília, ano 11, n 55, p. 17 - 22. Jul/set 1992.

SOUSA, R. F. e SÁ CARNEIRO, C. C. B. Parâmetros Curriculares Nacionais para - ensino de Ciências Naturais: desafios para a ação docente. Curitiba: Prismas. 2013.

TEIXEIRA, F. M. \& SOBRAL, A. C. M. B. Como novos conhecimentos podem ser construídos a partir dos conhecimentos prévios: um estudo de caso. Ciência \& Educação, v. 16, n. 3, p. 667-677, 2010.

VILANOVA, R. e MARTINS, I. Educação em ciências e educação de jovens e adultos: pela necessidade do diálogo entre campo e práticas. Ciência \& Educação. V. 14, n. 2, p. 331 -346. 2008.

Recebido em: Abril de 2017 Aceito em: Abril de 2017 